\section{Viscosity of Associated Liquids}

AN equation representing the temperature variation of the viscosity $(\eta)$ of water and lime soda glass has just been published by Douglas ${ }^{1}$, namely,

$$
\eta=T\left(A^{\prime} e^{B^{\prime} / T}+C^{\prime} e^{D^{\prime} / T}\right) \text {, }
$$

where $A^{\prime}, B^{\prime}, C^{\prime}$ and $D^{\prime}$ are constants, and $T$ the absolute temperature.

I have recently shown ${ }^{2}$ that for non-associated liquids we may write :

$$
\eta \sqrt{v}=A e^{B / T}
$$

where $v$ is the specific volume.

(2) differs from the well-known Andrade-Guzmán equation by the occurrence of $\sqrt{v}$ in the variable $\eta$, a difference which, although not affecting the accuracy of the equation (for within any temperature range the variation in viscosity is many times greater than the corresponding change in $\sqrt{v}$ ), leads to a tolerably constant value of $\eta_{c} \sqrt{v_{c}}$, the value of $\eta \sqrt{ } \bar{v}$ at the critical temperature.

For associated liquids, I found that the addition of a second exponential term to (2) gives an equation which is in good agreement with the experimental data :

$$
\eta \sqrt{v}=A e^{B / T}+C e^{D / T} . . .
$$

(3) is, of course, a modification of (1) and has been fitted to the experimental results for a number of substances. A typical case is that of $\mathbf{2 \cdot 2}$ dimethyl butanol I :

$\begin{array}{lccccccc}\text { Temperature }{ }^{\circ} \mathrm{C} . & 5 & 15 & 25 & 35 & 45 & 55 & 65 \\ \eta \sqrt{v} \text { calc. }(\eta \text { in } & & & & & & & \\ 10^{3} \text { poise) } & 352 \cdot 7 & 177 \cdot 5 & 98 \cdot 2 & 59 \cdot 3 & 38 \cdot 7 & 26.95 & 19 \cdot 76 \\ \eta \sqrt{v} \text { expt. } & 350 \cdot 2 & 176 \cdot 9 & 99 \cdot 6 & 60 \cdot 0 & 39 \cdot 2 & 27 \cdot 27 & 19 \cdot 94 \\ \text { Temperature }{ }^{\circ} \mathrm{C} . & 75 & 85 & 95 & 105 & 115 & 125 & \\ \eta \sqrt{\bar{v}} \text { calc. }(\eta \text { in } & & & & & & & \\ 10^{3} \text { poise) } & 15 \cdot 10 & 11 \cdot 90 & 9 \cdot 62 & 7 \cdot 93 & 6 \cdot 64 & 5 \cdot 635 & \\ \eta \sqrt{v} \text { expt. } & 15 \cdot 11 & 11 \cdot 84 & 9 \cdot 52 & 7 \cdot 89 & 6 \cdot 64 & 5 \cdot 670 & \end{array}$

Values of the constants $A, B, C$ (as $-\log _{10} C$ ) and $D$ for a number of alcohols which are known to give a markedly non-linear relationship between $\log \eta \sqrt{v}$ and $1 / T$ are tabulated below, together with the average percentage deviations between the

\begin{tabular}{|c|c|c|c|c|c|c|}
\hline Substance & $B$ & $D$ & $A$ & $-\log _{10} C$ & Mean & \\
\hline $\begin{array}{l}\text { Waters } \\
\text { Ethylene glycol }{ }^{4} \\
\text { Tert. butyl alcohol } 5 \\
\text { Tert. amyl alcohol } \\
\text { 'Active' amyl }\end{array}$ & $\begin{array}{l}1,247 \\
2,234 \\
2,250 \\
2,199\end{array}$ & $\begin{array}{l}77 \\
70 \\
11 \\
47\end{array}$ & $\begin{array}{l}0.09464 \\
0.04445 \\
0.01121 \\
0.01351\end{array}$ & $\begin{array}{l}5 \cdot 0652 \\
6 \cdot 2535 \\
9 \cdot 3206 \\
7 \cdot 3949\end{array}$ & $\begin{array}{l}0 \cdot 2 \\
1 \cdot 0 \\
1 \cdot 1 \\
1 \cdot 7\end{array}$ & $\begin{array}{c}2 \cdot 84-17 \cdot 9 \\
10 \cdot 4-199 \\
6 \cdot 00-33 \cdot 5 \\
4 \cdot 34-142\end{array}$ \\
\hline $\begin{array}{l}\text { alc } \\
\text { Hexa } \\
\text { Hexa } \\
\text { Hept } \\
\text { 2.2.di }\end{array}$ & $\begin{array}{l}\mathbf{2 , 0 3 0} \\
108 \cdot 2 \\
1,540 \\
1,437\end{array}$ & $\begin{array}{l}3,742 \\
2,777 \\
4,468 \\
3,035\end{array}$ & $\begin{array}{l}0 \cdot 02050 \\
0 \cdot 9817 \\
0 \cdot 07927 \\
0 \cdot 09070\end{array}$ & $\begin{array}{l}4 \cdot 0 \\
2 \cdot 3 \\
4 \cdot 9 \\
2 \cdot 8\end{array}$ & $\begin{array}{l}0 \cdot 5 \\
0 \cdot 4 \\
0 \cdot 4 \\
0 \cdot 3\end{array}$ & $\begin{array}{l}5 \cdot 05-111 \\
3 \cdot 45-89 \cdot 2 \\
3 \cdot 83-108 \\
4 \cdot 50-100\end{array}$ \\
\hline 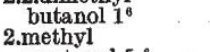 & 2,319 & 6,452 & 0.01584 & $7 \cdot 6227$ & 0.7 & $4 \cdot 86-321$ \\
\hline $\begin{array}{l}\text { nol } 5^{6} \\
\text { butanol } 1^{6}\end{array}$ & $\begin{array}{l}1,127 \\
1,670\end{array}$ & $\begin{array}{l}2,925 \\
4,378\end{array}$ & $\begin{array}{l}0 \cdot 1120 \\
0 \cdot 06250\end{array}$ & $\begin{array}{l}2 \cdot 6009 \\
4 \cdot 7077\end{array}$ & $\begin{array}{l}0.7 \\
1 \cdot 7\end{array}$ & $\begin{array}{l}3 \cdot 74-90 \cdot 9 \\
3 \cdot 61-146\end{array}$ \\
\hline $\begin{array}{l}\text { pen } \\
\text { 2.met }\end{array}$ & 94 & 88 & $0 \cdot 1540$ & 141 & 0.8 & $3 \cdot 74-96 \cdot 2$ \\
\hline per & 1,926 & 5,735 & 0.02713 & $7 \cdot 0086$ & $1 \cdot 8$ & $3 \cdot 15-102$ \\
\hline pentanol & 1,418 & 4,380 & $0 \cdot 09482$ & $4 \cdot 0246$ & $1 \cdot 1$ & $3 \cdot 66-73 \cdot 4$ \\
\hline
\end{tabular}
observed and calculated values of the viscosity. The observers are indicated by references to footnotes.

Department of Chemical Engineering,

L. H. Thomas

School of Mines and Technology,

Treforest. Sept. 27.

1 Nature, 158, $415(1946)$.

2 Thomas, J. Chem. Soc., 573 (1946).

" "International Critical Tables."

- Bingham and Fornwalt, J. Rheol., 1, 372 (1930).

'Thorpe and Rodger, Phil. Trans., 185, 397 (1894).

- Hovorka, Lankelma et al., J. Amer. Chem. Soc., 55, 4820 (1933); 60,820 (1938); 62, 187, 1096, 2372 (1940); 68, 1097 (1941).

\section{The Logarithmic Transformation}

IN a recent communication, Dr. H. V. Musham ${ }^{1}$ directs attention to the fact that a logarithmic transformation of a variable may not only make the distribution more normal but will often stabilize the standard deviation, that is, make it more or less independent of the mean in those cases where the standard deviation of the original variable is roughly proportional to the mean. He is, perhaps, mistaken when he suggests that the latter effect has not previously been appreciated. In cases where the logarithmic transformation is used as a preparatory step to an analysis of variance, its main purpose is to ensure that the standard deviation, as calculated from a residual sum of squares, shall be applicable to the various 'treatment' means, even when these differ considerably from each other. The lack of normality of the distribution of the residual error is not in itself of any great practical consequence.

There is yet another useful property of the logarithmic transformation which is often not appreciated. If natural logarithms are used, we have

$$
\begin{aligned}
y & =\log x \\
d y & =d x / x .
\end{aligned}
$$

If variations in $x$ are not too large, we may put $x=\mu$, its mean value. Then

$$
d y=d x / \mu,
$$

$\therefore$ standard deviation $(y)=$ standard deviation $(x) / \mu$ $=$ coefficient of variation $(x)$.

Hence, the coefficient of variation of $x$ is given directly by the standard deviation of $y=\log x$, which can be estimated by the usual method from

$$
s=\sqrt{ }\left\{\Sigma(y-\bar{y})^{2} /(n-1)\right\} .
$$

If common instead of natural logarithms are used, the standard deviation of $y$ must be multiplied by $2 \cdot 30259$ to give the coefficient of variation of $x$.

Research Department,

W. L. Strevens

Imperial Chemical Industries, Ltd.,

Billingham, Co. Durham.

${ }^{1}$ Nature, 158, 453 (1940)

\section{Activity of 'Vitamin A-Acid' in the Rat}

Ir is a well-known fact that $\beta$-carotene is converted by mammals into vitamin $A$, which is stored in the liver. As vitamin A-acid is biologically active ${ }^{1}$, it seemed possible that this substance might also be converted into vitamin A. To investigate this question the following experiments were carried out.

Young rats were grown on a diet freed of vitamin A. After signs of deficiency had appeared, the rats were divided into groups of five animals. From one group the vitamin A content of the livers was determined after saponification. (The vitamin A determinations were carried out by the Analytical Department using the Carr and Price reaction and the Lovibond colorimeter.) This proved to be zero. The rats of a second group each received subcutaneously $10 \mathrm{mgm}$. of vitamin A-acid as sodium salt dissolved in 2 c.c. phosphate buffer $(p H \mathbf{H} \cdot 5)$. These injections caused no serious damage. After three days the vitamin A content of the livers was determined. It proved to be zero. 